the motives as well as the views of Dr. Winslow. But this was surely unnecessary. All that can, in our opinion, be said in the matter, is, that $\mathrm{Dr}$. Winslow made a mistake in diagnosis, as others have done before him, and will do to the end of time."-British Medical Journal, June 4.

\title{
Professor Lraycock on the Medico-legal relations of Insanity, with reference to the Townley case.
}

"On a former occasion I called attention to the case of $\mathbf{M r}$. Windham, and showed how faulty the English system of jurisprudence was in cases like his, inasmuch as it made no proper distinction between mental diseases and deficiencies. The question put to the jury was whether $\mathbf{M r}$. Windham was insane-a highly theoretical question in itself, but wholly inapplicable to his case, inasmuch as the true question was whether he was competent or not to manage his large property. The result of the trial was plain enough from the first. He was found to be not insane, and was left to his own discretion, or rather indiscretion, to do with his property as he pleased, and which he appears to have wholly squandered since the trial. Now, if the true issue had been put to the jury, founded on the scientific distinction between mental diseases and defects, Mr. Windham would have been protected, just as a minor in law is protected, from the evil consequences of his youthful defects in judgments. At the same time I called attention to the case of Clark, a lunatic, who was condemned at Newcastle to be hung. but whose sentence was commuted to penal servitude for life, owing to the most obvious defects in the English principles of jurisprudence in regard to the responsibility of the insane. A similar case has very recently attracted public attention. George Victor Townley was tried at Derby on 11th December last for the murder of a young lady who had been engaged to marry him, but had discarded him for another. He was found guilty, and sentenced to be hung; but the judge (as in Clark's case) immediately communicated to Sir George Grey his doubts whether the sentence should be carried into execution. Two points arose in this case-first, whether Townley was insane at the time he committed the murder? secondly, whether he was insane at the time he was condemned? Dr. Forbes Winslow gave his opinion in the affirmative as to both these questions, and this view was confirmed by other competent observers. Mr. Gisborne, surgeon to the prison; Mr. Harwood, a medical practitioner ; four Derbyshire magistrates; and three Commissioners in Lunacy, accustomed to investigate such cases, all concurred in opinion that he was at least not of sound mind when condemned. Execution of sentence was therefore deferred, and the patient was sent to Bethlehem Hospital for the Insane, or Bedlam, as it is popularly termed. Here, however, he was subjected to other examinations by four eminent and experienced practitioners in insanity - namely, Drs. Hood and Bucknill, Chancery Visitors in Lunacy ; Dr. Meyer, Medical Superintendent of the Criminal Lunatics' Hospital at Broadmoor; and Dr. Helps, resident physician to Bethlehem Hospital. They also carefully examined the official documents bearing on the case, and arrived unanimously at the conclusion that George Victor Townley was of sound mind. Like Clark, he was then sent to penal servitude for life. It is not surprising that these contradictory opinions expressed in the highest quarters, medically speaking, have caused both controversy and serious reflection. If men so eminently qualified differ, how can less experienced practioners be expected to sign certificates of lunacy which shall not be open to doubt? And how will they fare in courts of law? That much may be said on both sides is proved by the discussions for or against 
Townley, as patient or criminal, which have taken place in both medical and non-medical circles. Drs. Robertson and Maudsley, for example, the editors of the 'Journal of Mental Science,' and with ample experience of mental diseases, take up excellent ground on one side; while 'A Voice from Derby to Bedlam,' ably and warnily advocates the other. Why is there this discrepancy? And if such high medical authorities cannot decide, who can? In these remarks I fully concede that to expect unanimity upon all questions of the class to which insanity belongs is futile; a certain amount of difference of opinion will surely arise under any circumstances. Consider how the highest legal authorities in successive discussions in different courts of appeal have been almost equally divided as to the interpretation of the law in the case of the ship Alexandra, and I think we may fairly judge leniently the like differences of medical opinions manifested in even such a case as that of Townley. . . . . .

"It is not a larger experience, however, but a better knowledge of principles that is mainly needed to this end. In the case of Townley the best experience was made available to the public service, yet on one side or the other it was surely wrong. Now, it is always the principles of a science which guide observation and correct experience, and it is therefore the principles of medical psychology which would guide us in this as well as other instances; for our science differs fundamentally from mental philosophy or 'metaphysics in this, that it seeks to determine what are the morbid changes in the structure and functions of the brain which lead to mental disorder and disease, and how they are caused. It deals practically with the organ, and not with abstract notions as to mind, which never have been, and never can be made available to the practical ends of a science of mind. If Townley was, or is, or has been insane, he had or has disorder or defect of brain-function of a nature and induced by causes which medical psychology expounds, or ought to expound. Now, there cannot be a doubt that he was so constituted naturally as to be easily influenced by those causes which excite disurdered action of the brain. He had an hereditary predisposition to insanity. If this was excited into activity in him, it was by 'a disappointment in love,' for the whole history of his case shows that his brain and nervous system did experience a shock when the object of his passion discarded him for another. Now, medical psychology inquires into the origin of the instinct, passion, or sentiment of love of the sexes, and determines how by its healthy or morbid action on the brain it develops or disorders the faculties and propensities. The strength of the passion is too well known, morally, to require comment ; but how it arises physiologically, so as to change the whole man or woman as if by enchantment, and how it acts in causing disorder and disease of the brain, 80 as to lead to suicide, homicide, theft, cunning, malice, and inconceivable follies in life and conduct, rending in pieces the whole mental framework by its action on and through the bodily organs and organization, are within the sphere of medical psychology, as a science, exclusively ; and perhaps that which treats of the physiology and pathology of this passion is the most wonderful part of the science. If I might venture an opinion on the facts of Townley's case, as elucidated by such principles, I should incline to say he was insane. Those facts, are, however, somewhat defective in number and details, for science teaches us how and what to observe, as well as how to deduce from observation. Herein, indeed, would be the great gain to the profession and the public if medical psychology were taught in all our medical schools."-Professor Laycock's Introdwctory lecture to his course of Medical Psychology. May 4. 